\title{
Unprovoked or provoked venous thromboembolism: not the prevalent criterion to decide on anticoagulation extension in clinical practice of various countries - the prospective, international, observational WHITE study
}

\author{
Gualtiero Palareti ${ }^{1}$ (D) Angelo Bignamini ${ }^{2} \cdot$ Michela Cini $^{1} \cdot$ Young-Jun $\mathrm{Li}^{3} \cdot$ Tomasz Urbanek $^{4}$. Juraj Madaric ${ }^{5}$. \\ Kamel Bouslama ${ }^{6}$. German Y. Sokurenko ${ }^{7}$. Giuseppe M. Andreozzi ${ }^{8}$. Jiří Matuška ${ }^{9}$. Armando Mansilha ${ }^{10}$. \\ Victor Barinov ${ }^{11} \cdot$ for the WHITE study group
}

Received: 16 March 2021 / Accepted: 13 May 2021 / Published online: 27 July 2021

(c) The Author(s) 2021

\begin{abstract}
The decision on treatment after a first venous thromboembolism (VTE) to prevent recurrences may be influenced by many factors. The prospective, observational, WHITE study aimed to analyze how this issue was tackled in every-day clinical practice in various countries, which have sensibly different socio-economic conditions and healthcare systems. Doctors active in 79 Internal or Vascular clinical centers in 7 countries (China, Czechia, Poland, Portugal, Russia, Slovakia, and Tunisia) enrolled VTE patients after the maintenance treatment phase. The present report analyzed information, collected in the central database, regarding the baseline characteristics, index events, type and duration of anticoagulant therapy and decision on post-maintenance treatment. From April 2018 to December 2020, 1240 patients were enrolled, 58\% with an unprovoked index event. Direct oral anticoagulants (DOACs) were used in $>85 \%$ of all cases in China, Poland, Portugal, Russia and Czechia, in 52\% in Slovakia and in no patient in Tunisia. The maintenance anticoagulation lasted in average approximately 6 months. Altogether, anticoagulation was stopped in 20\%, extended in about 50\%, regardless of whether the event was unprovoked or provoked and shifted to antithrombotics (mainly sulodexide or aspirin) in the remaining patients. In conclusion, some differences in VTE patient management were found between countries. The provoked/unprovoked nature of the index event, instead, was not the prevalent criterion to drive the decision on extension of anticoagulation, without large variations between countries. DOACs were the most widely used anticoagulant drugs, whereas $>25 \%$ of patients received antithrombotic drugs instead of anticoagulants as extended treatment.
\end{abstract}

Keywords Venous thromboembolism $\cdot$ Anticoagulation $\cdot$ Anticoagulants $\cdot$ Antithrombotics $\cdot$ Sulodexide $\cdot$ Aspirin

Members of the "for the WHITE study group" are listed in

acknowledgements section.

Gualtiero Palareti

Gualtiero.palareti@unibo.it

1 Arianna Anticoagulazione Foundation, Via Paolo Fabbri 1/3, 401138 Bologna, Italy

2 School of Specialization in Hospital Pharmacy, University of Milan, Milan, Italy

3 Peking Union Medical College, Chinese Academy of Medical Sciences, Beijing, China

4 Medical University of Silesia, Katowice, Poland

5 Clinic of Angiology, Comenius University and National Institute of Cardiovascular Diseases, Bratislava, Slovakia
6 Faculty of Medicine of Tunis, Tunis, Tunisia

7 North-West Mechnikov State Medical University, St. Petersburg, Russia

8 Angiology Unit, University of Padua, Padua, Italy

9 Clinical Trial Centre, Hodonin, Czech Republic

10 Faculty of Medicine, University of Porto, Porto, Portugal

11 Central State Medical Academy of the Office of the President of the Russian Federation, Clinical hospital N. 1

"Volynskaya", Moscow, Russia 


\section{Introduction}

The guidelines [1] recommend initial treatment of deep vein thrombosis (DVT) of the lower limbs and/or pulmonary embolism (PE) with a parenteral direct-acting anticoagulant or direct oral anticoagulant (DOAC), followed by a period of anticoagulation therapy with a vitamin $\mathrm{K}$ antagonist (VKA) or, preferably, a DOAC, or low molecular weight heparin (LMWH), particularly in patients with cancer-associated thrombosis. Anticoagulation therapy is essential for at least 3-6 months in all cases [2], whereas a longer treatment is intended to decrease the risk of recurrences. The incidence of venous thromboembolism (VTE) recurrence is very low when an event is provoked by surgery or another specific strong and removable risk factor. In these cases, a three- to sixmonth treatment (defined as "maintenance" treatment period) is considered sufficient. Conversely, the risk of recurrence is reported very high in subjects with permanent and strong risk factors, such as cancer, inflammatory diseases, serious acquired or inherited thrombophilic alterations, repeated VTE events, or when the first event was life-threatening. In these cases, an indefinite anticoagulant treatment is recommended. A significant number of VTE patients, however, have events without any apparent risk factors (unprovoked), or associated with weak risk factors. In these patients, an anticoagulant treatment limited to the maintenance phase may not be sufficient and international guidelines suggest an extended (indefinite, i.e., without a predetermined stop date) anticoagulation, provided that the risk of bleeding associated with anticoagulation is not high [1].

In line with international guidelines, at the end of the maintenance period, all patients with an acute VTE event, should be evaluated for their risk of recurrence and of bleeding, and the attending physician must decide what to do next. The possible options are (a) interrupt any specific pharmacological treatment; (b) continue with extended anticoagulation using the same or another anticoagulant drug, at standard or reduced dosage; or (c) replace the anticoagulant in use with an alternative antithrombotic drug. However, the individual patient's risks are not always easy to be estimated. A number of additional factors may also influence the clinical decision, including subject's preferences, concurrent diseases and treatments, healthcare system support, and availability of potentially effective treatments alternative to anticoagulation. In addition, based on the local healthcare system, not all regimens can be protracted indefinitely in all cases. Little is known as to which proportion of subjects is assigned to these alternatives and whether this proportion is equivalent across different healthcare systems. After the decision is taken, a number of validated data are available in the literature regarding the outcomes in subjects assigned to extended anticoagulation for up to 1 year [3-9], whereas little if any information is available for subjects receiving extended anticoagulation for more than one year, or assigned to alternative long-term treatment, or who stopped the treatment. Furthermore, little is known about the actual practice concerning this issue in countries of different geographic areas, differing for socio-economic conditions and healthcare systems.

The international WHITE study was intended to analyze data on these issues collected from the every-day clinical practice in various countries which have sensibly different socio-economic conditions and healthcare systems.

\section{Materials and methods}

\section{Study design, participants, and study population}

WHITE was a multicenter, multinational, observational, noninterventional, investigators-initiated, no-profit, prospective study (ClinicalTrials.gov Identifier: NCT04646993), dedicated to evaluating the decisions taken by clinicians at the end of the maintenance treatment of subjects with a firstever event of DVT of the lower limbs and/or pulmonary embolism. The study was an independent research initiative promoted by the "Arianna Anticoagulazione" Foundation (Bologna, Italy), and managed in collaboration with a Core Team of vascular-experts professionals (the detailed list of the study boards and their compositions is shown in Appendix 1). One Country Coordinator for each active country, appointed by the Foundation, invited local clinical vascular centers to participate in the study, and collaborated with local contract research organizations (CRO) to obtain authorization to the study from the national Health Authority Boards and the local Ethics Committees. The study was carried out and reported according to the "Strengthening the Reporting of Observational Studies in Epidemiology (STROBE)" guidelines for observational studies [10].

The study aimed at enrolling patients during the maintenance treatment after diagnosis of a first DVT and/ or PE event. Patients of any ethnicity, male and female, aged $\geq 18$ years, were eligible for the study if treated with anticoagulant therapy for 3-12 months following a documented first-ever event of provoked or unprovoked DVT of the lower limbs and/or of PE. Subjects provided a written informed consent before inclusion in the study. Excluded from the study were subjects $<18$ years old, with thrombosis in other sites, unable or unwilling to give written informed consent (complete list of inclusion/exclusion criteria in the Protocol, available on request). Each subject had the right 
to refuse continuing the study at any moment and without justifications.

The primary objective of the study was to assess the clinicians' decisions on the modality to manage the secondary prevention in patients after a first VTE episode, at the end of the maintenance period of anticoagulation considered standard, and the reasons guiding the physician's decision. Secondary objective was the recording of thromboembolic or bleeding complications, and of deaths occurring during follow-up. The study encompassed two sections: (a) a transversal section, in which the primary objectives were evaluated; and (b) a longitudinal section, in which the secondary objectives were evaluated. The type, dose and duration of patients' treatment before and after inclusion in the Study were left at the attending physician's discretion.

\section{Data collection and management}

All participants in the WHITE study recorded the information collected in a structured case report form (CRF;) onto a secure, web-based central electronic database designed and managed by Officinebit (Switzerland) and were controlled at the study coordinating center (Arianna Anticoagulazione Foundation) by a dedicated study-monitor (C.M.) who-when necessary - sent data queries to participating sites to ensure completeness and accuracy. All patients were assigned a unique identifier, and personally identifiable data were removed at the participant's side to ensure anonymity.

The scope of the present analysis is limited to the transversal section of the study, including the baseline patient conditions, the index VTE events with associated risk factors, the maintenance treatment of the events, and the clinicians' decisions on the management of patients regarding the secondary VTE prevention. The site of index VTE events was classified in (a) DVT, when thrombosis involved proximal veins (extending or not to calf deep veins) without diagnosed PE; (b) IDDVT, when thrombosis was limited to calf (distal) deep veins; (c) PE ( \pm DVT), when an objectively documented PE occurred in the absence or in presence of a DVT (proximal or distal). The available data regarding the objective conditions of the affected lower limb with assessment of post-thrombotic syndrome and the longitudinal section of the study, including the events recorded during follow-up in patients after they received the management decision will be reported subsequently.

\section{Statistical analysis}

Data have been analyzed with SPSS version 24 integrated for specific items with $\mathrm{R}$ version 3.6.1. All variables have been summarized with the usual descriptive techniques. Demographic and clinical variables were compared, when needed, with the Chi-square or Fisher's test for nominal variables, and ANOVA, integrated where appropriate with the posthoc pairwise Tukey HSD test, for the continuous variables. Only when absolutely needed, we used the non-parametric approach (Mann-Whitney and Kruskal-Wallis tests). The proportion of choices made by the attending physician was reported as proportion with confidence interval. The primary analysis tested by goodness-of-fit whether the choices were random or not. The impact of demographic and prognostic factors-including the country-on the choice was tested by chi-square and, where appropriate, logistic regression analysis.

\section{Funding}

The "Arianna Anticoagulazione" Foundation (Bologna Italy) promoted the WHITE study. Public and private institutions, companies and individuals interested in the issue of anticoagulant or antithrombotic treatments (manufacturers of drugs or other goods and services) were asked by the Executive Committee of the Foundation to help fund the promoted studies via unrestricted grants without any right to access the database. Members of the Foundation's Executive Committee do not receive any payment or fee for their work with the Foundation. The Foundation has received an unrestricted research grant from Alfasigma (Bologna, Italy), specifically dedicated to the realization of this study.

\section{Availability and cost of VTE treatments in the countries involved in the study}

The specificities of the individual healthcare systems were considered factors potentially able to influence the monitored outcomes. A pre-study survey, performed with the participation of the National Coordinators, singled out similarities but also important differences. VKA anticoagulants were available in all countries and free of charge except in Tunisia. LMWH were equally available in all countries and free of charge except in Poland, Slovakia, and Tunisia, where they were available at an average daily cost of $€ 1, € 5$, and $€ 8$, respectively. The status of the direct oral anticoagulants (DOACs) was highly variable. No DOAC was being marketed in Tunisia, whereas all DOACs were available in Czechia and, except edoxaban, in China and Slovakia. Rivaroxaban was available in all countries; in Poland, also dabigatran was available. DOACs were free of charge in Czechia and almost free in Slovakia. The cost of one month of DOAC treatment at standard dose was of $€ 25-30$ and $€ 35$ for rivaroxaban and dabigatran, respectively, in Poland, and of $€ 120$ in Russia for rivaroxaban. In China, the daily treatment cost with DOACs ranged from 10 to 20 euro. Low-dose ASA (Cardioaspirin ${ }^{\circledR}$ ) was available in all countries and free of charge except in Tunisia ( $€ 1$ per month) and Poland (€ 2 per month). Sulodexide was available in all countries but in 
none was it free of charge. Follow-up visits for VTE patients were recommended by all the National Healthcare Systems except in China and were free of charge in Czechia, Poland, and Slovakia.

\section{Results}

The enrollment of patients started on April 2018. Recruitment was severely delayed by slow bureaucratic approval procedures (particularly in some countries) and the effects of SARS-CoV-2 pandemics, that substantially limited the capacity of recruitment. The Foundation decided to stop inclusion of new patients on December 15, 2020, when 1240 valid patients (Fig. 1) had been recruited by 79 active clinical sites (the complete list of active clinical centers is reported below), in 7 countries (Table 1).

\section{Baseline characteristics and index events}

Caucasian subjects were the most prevalent (69\%). Age and sex distribution did not differ among countries, whereas BMI was significantly lower in Chinese subjects versus all the others (Table 1). The prevalence of hypertension was lowest in Tunisia and China (about $28 \%$ in both countries), and highest in Russian patients (45.7\%), who also reported the highest prevalence of ischemic heart disease $(16.8 \%)$ and of smokers (24\%). No differences were detected among countries for the presence of diabetes or cerebrovascular diseases. Only 18 patients reported kidney failure, almost one-third of whom (5 cases) from Poland.

The distribution of the index event (Table 1) was significantly different by country $(P<0.001)$, essentially because the rate of the reported PE in the patients included into the study in Czechia was 1.6 to 3 times greater than in all other countries $(P=0.005)$. Among the patients with DVT, the most affected limb was the left (59\% vs. $45 \%$ of cases with right limb affected; $P<0.001)$.

The VTE events were classified unprovoked in 696 cases $(58 \%)$ and provoked in the balance. The classification differed significantly across countries $(P<0.001)$, with the proportion of unprovoked DVTs significantly below average in China and Czechia (Fig. 2). The distribution of risk factors for thrombosis agreed with the distribution as provoked or unprovoked (Supplemental Table $\mathrm{S}-1$ ), whereas no major differences were seen by index event (Supplemental Table S-2).

Fig. 1 Flow chart of investi-

gated patients

Initially included patients 1290

Patients excluded: $\mathbf{5 0}$

missing essential data: ${ }^{*} 32$ presence of exclusion criteria: 7 ID generated by mistake: 6 consent withdrawn: 2 duplicate case: 2 investigator's decision: 1

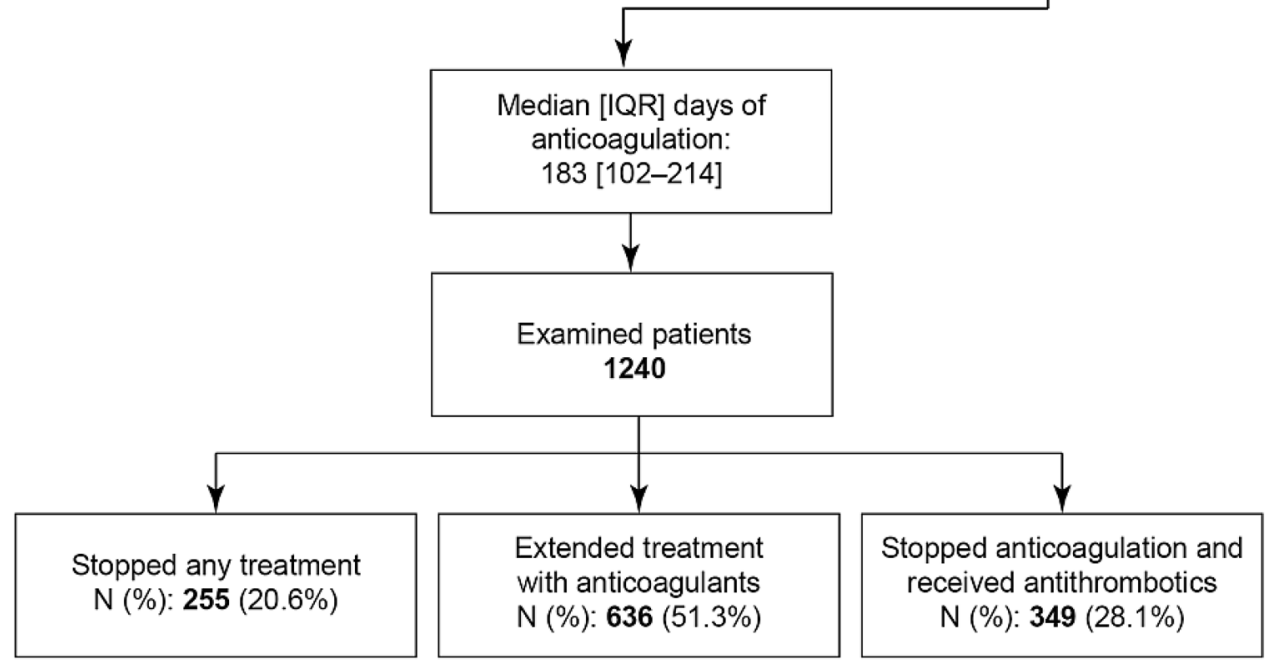




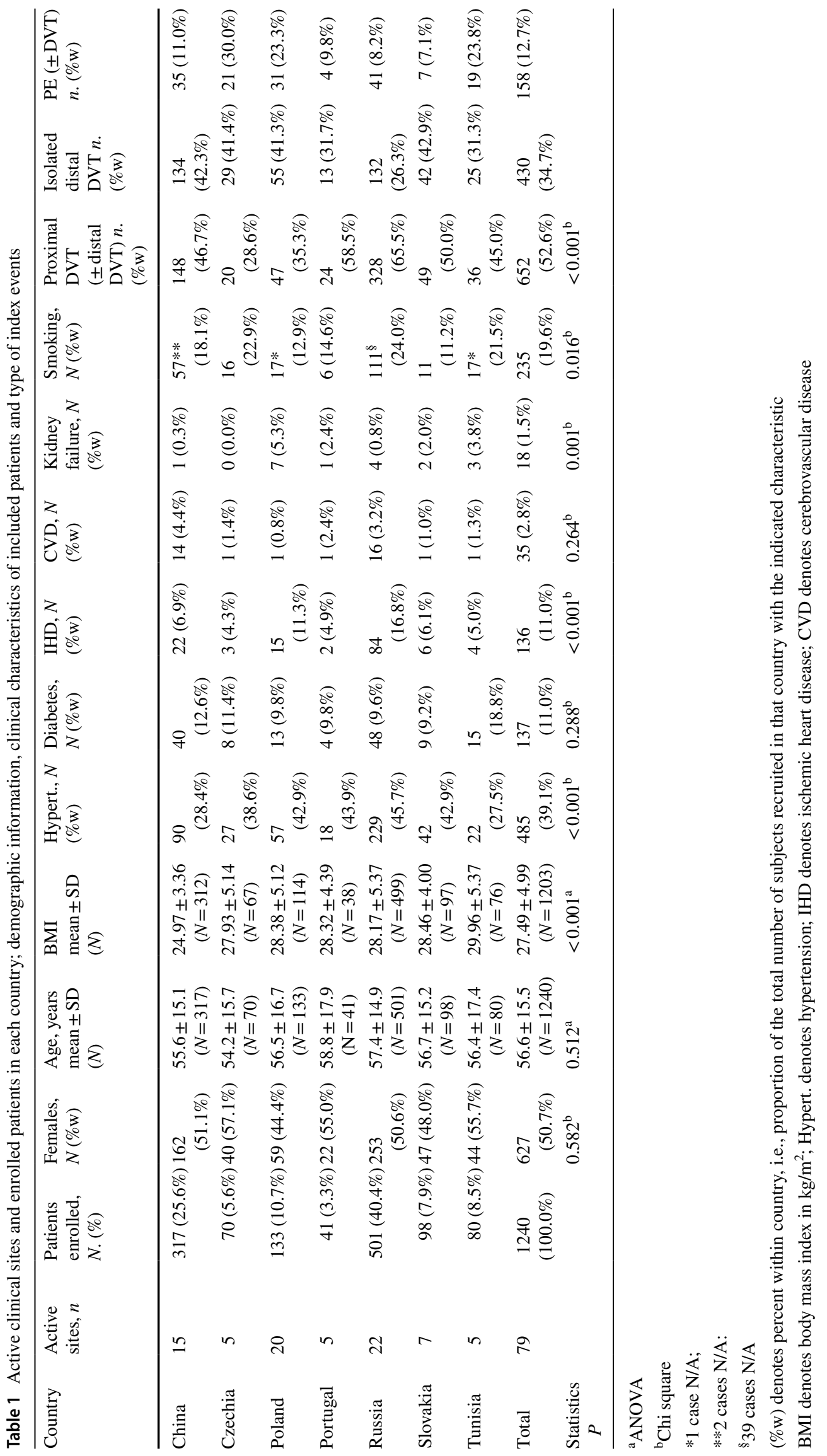




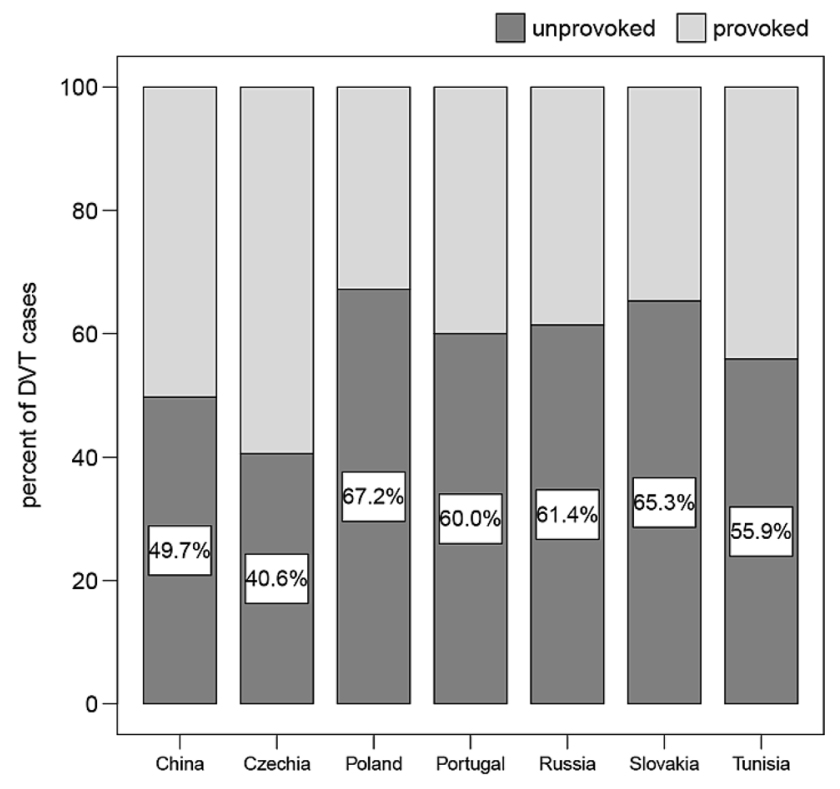

Fig. 2 Distribution by country of the index events as provoked or unprovoked

\section{Treatment during maintenance phase}

The classes of anticoagulant drugs used during the maintenance treatment phase differed between countries. The distribution of treatments privileged the direct oral anticoagulants (DOACs), which were used in 86-94\% of cases in China, Poland, Portugal, Russia, and Czechia, 52\% in Slovakia and were not used in Tunisia, where VKAs were instead used in $86 \%$ of subjects. There was no difference of treatment by index event (Supplemental Table S-3), nor by type of event, although the IDDVT represented a significantly greater fraction of the provoked events (Supplemental Table S-4).

In average, the maintenance anticoagulation had lasted approximately 6 months at the time of the decision; however, it was the shortest in China (mean \pm SD: $164 \pm 83$ days) and the longest in Tunisia $(205 \pm 68)$ and Czechia $(196 \pm 82)$. The anticoagulation duration in case of unprovoked events was in average slightly longer than in provoked events, but the difference was statistically significant only in Czechia $(P=0.006)$ and Slovakia $(P=0.007)$. Only very few patients (none in Czechia) received a maintenance anticoagulation for $<90$ days, while a treatment for $>180$ days was given to a proportion of patients ranging from $34.4 \%$ (China) to $65.4 \%$ (Tunisia; Fig. 3).

\section{Decision about extension of treatment}

In about $20 \%$ of patients, the attending physician decided to stop the anticoagulant treatment (Table 2); an extension of anticoagulation (whatever the drug used) was decided in

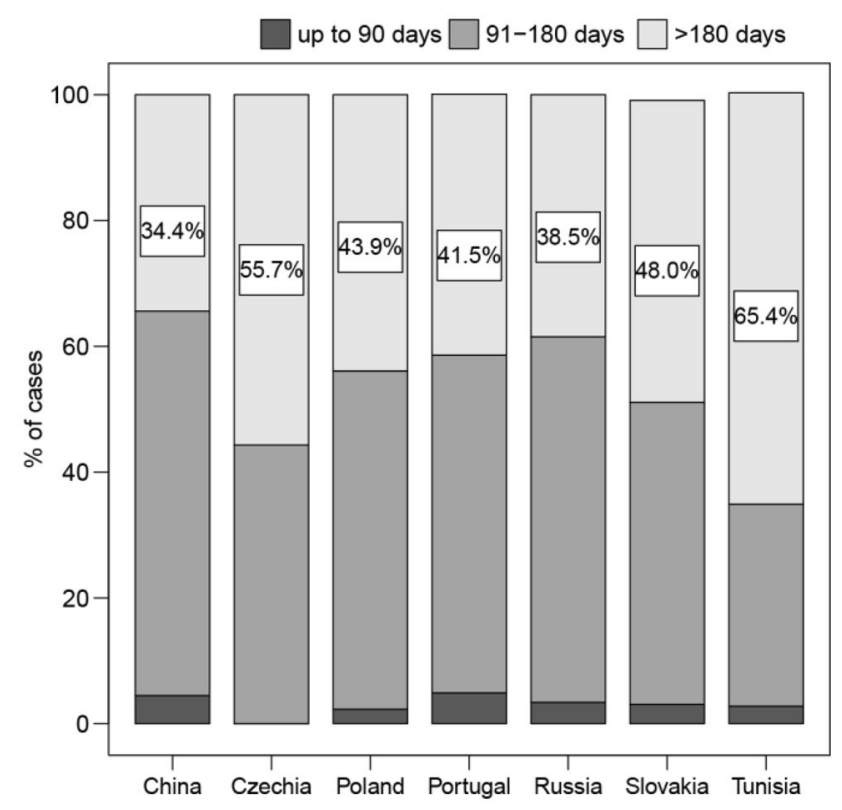

Fig. 3 Distribution by country of maintenance anticoagulation duration

more than half the patients $(51.3 \%)$, whereas in $28.1 \%$ of them, an antithrombotic drug (sulodexide or antiplatelets) was prescribed. The distribution of the decisions clearly differed from the uniform distribution $(P<0.001$, goodnessof-fit test), and differed significantly among countries. Discontinuation without replacement was decided in 27-40\% of cases in Portugal, Tunisia, and Czechia, vs. 3\% of cases in Slovakia. An extended anticoagulation was decided in 51-68\% of cases in Poland, Russia, China, and Portugal, vs. 25-26\% in Czechia and Tunisia. Continuation with other antithrombotics was decided in 38-60\% of cases in Poland, Tunisia, and Slovakia vs. $5 \%$ in Portugal. A DOAC was used in $85 \%$ of cases who extended anticoagulation; when continuing with the same anticoagulant, the dose was reduced in $17 \%$ of cases. Switching from one to another DOAC was reported in only 19 subjects. Overall, 351 subjects switched from the maintenance anticoagulation to prophylaxis with antithrombotic agents: sulodexide in 275 cases $(57 \%$ with the dose of $500 \mathrm{LSU} /$ day and the balance with $1000 \mathrm{LSU} /$ day), ASA in 72 (75-175 mg/day), clopidogrel in 6, and other treatments in 8 .

As shown in Table 3, anticoagulation was stopped in $15.4 \%$ and $28.9 \%$ and continued in $51.7 \%$ and $49.3 \%$ of patients who had unprovoked or provoked events, respectively. Anticoagulation was stopped in a minority of cases (about 13\%) and extended in more than half of patients when the index events were proximal with or without distal DVT, or PE (with or without DVT). Anticoagulation was stopped in one-third and extended in a similar proportion of IDDVT cases. The prescription of antithrombotics was higher when 
Table 2 Distribution of clinical decisions for the treatment of patients beyond the maintenance phase

\begin{tabular}{lccc}
\hline & $\begin{array}{l}\text { Anticoagulant treatment } \\
\text { was stopped, } N(\%)\end{array}$ & $\begin{array}{l}\text { Anticoagulant treatment } \\
\text { was extended, } N(\%)\end{array}$ & $\begin{array}{l}\text { Treatment continued with } \\
\text { antithrombotic agents, } N(\%)\end{array}$ \\
\hline China $N=317$ & $76(24.0 \%)$ & $190(59.9 \%)$ & $51(16.1 \%)$ \\
Czechia $N=70$ & $28(40.0 \%)$ & $18(25.7 \%)$ & $24(34.3 \%)$ \\
Poland $N=133$ & $15(11.3 \%)$ & $68(51.1 \%)$ & $50(37.6 \%)$ \\
Portugal $N=41$ & $11(26.8 \%)$ & $28(68.3 \%)$ & $2(4.9 \%)$ \\
Russia $N=501$ & $95(19.0 \%)$ & $275(54.9 \%)$ & $131(26.1 \%)$ \\
Slovakia $N=98$ & $3(3.1 \%)$ & $36(36.7 \%)$ & $59(60.2 \%)$ \\
Tunisia $N=80$ & $27(33.8 \%)$ & $21(26.3 \%)$ & $32(40.0 \%)$ \\
Total $N=1240$ & $255(20.6 \%)$ & $636(51.3 \%)$ & $349(28.1 \%)$ \\
\hline
\end{tabular}

the event was unprovoked $(32.9 \%)$ vs provoked $(21.8 \%$, $P<0.001$ ), and similar (about one-fourth of patients) in all types of events. The availability of recent ultrasound close to the decision favored the continuation with other non-anticoagulant antithrombotics rather than with anticoagulation; the same occurred among the unprovoked events, while among the provoked events it had no influence on the continuation with anticoagulation, whereas the absence of recent ultrasound favored stopping treatment (Supplemental Table S-5).

We examined whether the main demographic and prognostic factors might have influenced the decision taken. Sex, age and presence of cardiovascular risk factors did not significantly affect the choice of the regimen. The odds to continue with anticoagulation rather than stopping were higher among subjects with PE vs. those with only DVT [2.71 times $(1.59-4.61 ; P<0.001)]$ and in those with concomitant diseases $[1.49(1.07-2.06 ; P=0.018)]$. Limiting the analysis to the subjects with DVT, the odds to continue with anticoagulation rather than stopping was 1.88 [1.37-2.58; $P=0.001]$ among subjects with unprovoked DVT vs. those with provoked DVT and was $5.25[3.32-8.31 ; P<0.001]$ in subjects with vs. those without PTS signs. The odds to continue with other antithrombotics rather than stopping were higher in subjects with concomitant diseases [1.62 times (1.10-2.36; $P<0.001)]$, in those with unprovoked DVT [2.62 (1.83-3.75;P<0.001)] and in those with signs of PTS $[3.04(1.78 ; 5.22 ; P<0.001)]$. The complete results of the logistic regression analysis are reported in Supplemental Table S-6. We also collected information on the weight of other motivations as potential predictors of decision (Supplemental Table S-7), which will not be discussed here.

\section{Discussion}

This prospective study examined 1240 patients who had suffered from a first DVT and/or PE event and were enrolled during maintenance anticoagulation treatment in 79 clinical centers active in seven countries which differed by geographic area, socio-economic conditions, and health care systems. The main aims of the study were to investigate how the patients were managed in these countries, which anticoagulants and for how long were used for the maintenance treatment phase and which decision was taken about treatment after that phase. As expected, many differences were found among the countries and some similarities. While age and sex distribution did not differ in patients of the involved countries, the prevalence of hypertension and IHD was the highest in Russia, the country which also had the highest prevalence of smokers (24\%). The distribution of the index event reported in the study was significantly different by country. The most prevalent index event was proximal DVT (with or without involvement of distal veins), followed by isolated distal DVT; less frequent were cases of PE with or without DVT. DVT events involved 1.3 times more frequently the left rather than the right limb.

In all countries except Tunisia (where these drugs were not available), DOACs were the type of anticoagulant drug more often adopted for treatment during maintenance phase (Table 2); their use ranged between 52\% (Slovakia) and 94.3\% of patients (Czechia). Overall, DOACs were adopted in $84 \%$ of all patients (excluding those from Tunisia), a prevalence quite similar to that $(79.5 \%)$ recorded in a cohort of Italian VTE patients recently described [11]. These data show how widespread is the current DOAC use for VTE treatment in many countries (when available) and confirm the large preference for DOACs by treating physicians and patients as well.

In line with the international guideline [1], very few patients received a maintenance anticoagulant treatment for less than the recommended 90 days. The prevalent portion of patients received anticoagulant treatment for 3-6 months; however, a consistent portion of all patients (about 40\%) were treated for $>180$ days before being considered for possible extension of anticoagulation. The prevalence of a longlasting maintenance treatment was particularly evident in Tunisia (65.4\% of patients), where anticoagulation was performed with VKAs, and in Czechia (55.7\%), where DOACs were free. The mean duration of maintenance anticoagulation was not different between patients with unprovoked 


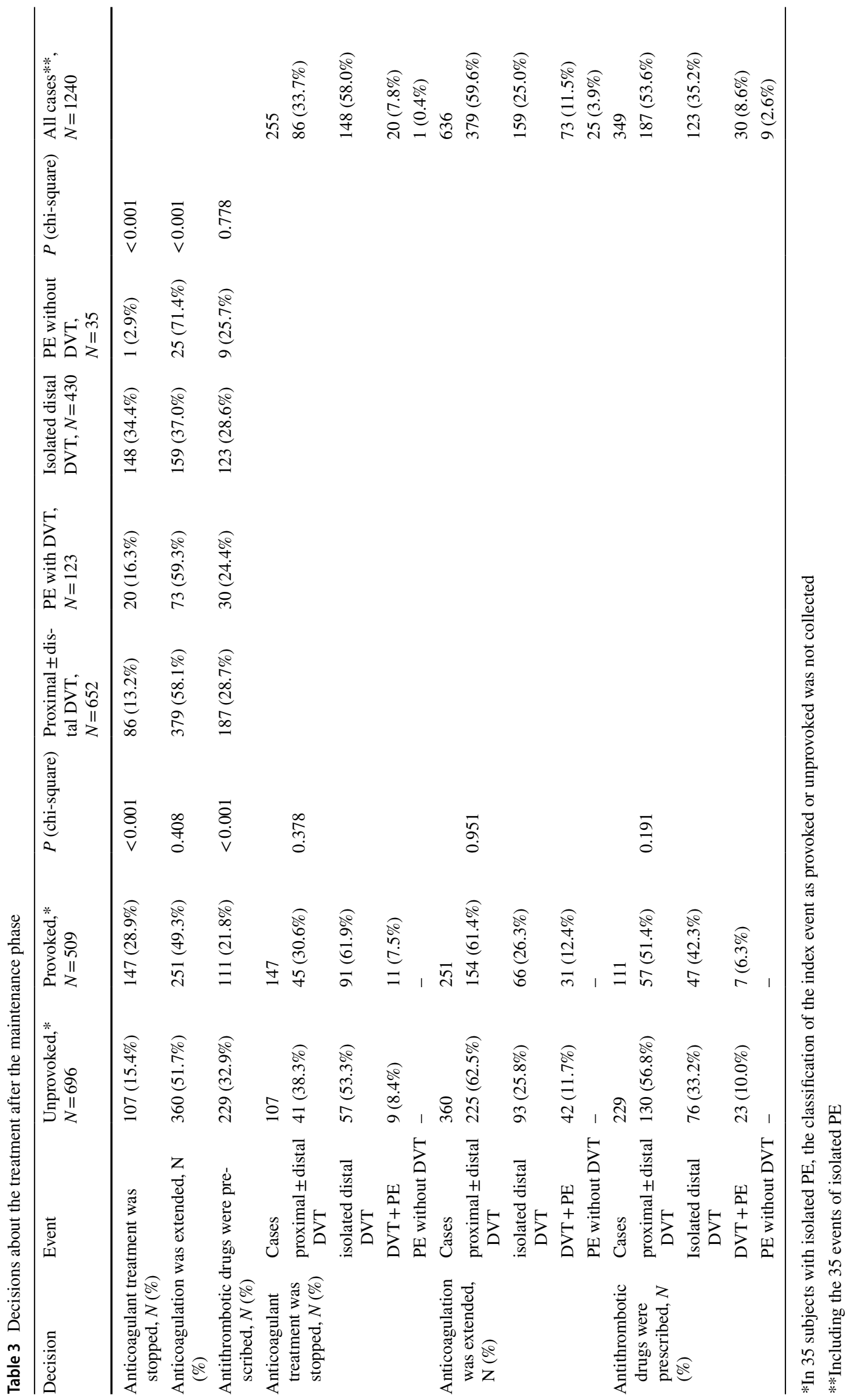


or provoked events in all the countries, with exception of Czechia and Slovakia, where unprovoked VTE patients were treated for a significantly longer period.

Not many studies have assessed the treatment of VTE patients in real-world populations. Among Italian VTE patients, prevalently managed by vascular doctors, an anticoagulation for $<3$ months was recorded in more patients (9\%) than found in the present study; conversely, quite similar (36.8\%) was the prevalence of patients who were treated for $>180$ days [12]. Completely different results were reported in a Canadian study [13], in which only $73 \%$ of patients with proven VTE were treated with anticoagulation (with VKAs) and for a much shorter period (median 61 days). These data, as well as those reported in the present study, depict how big are the differences among countries in the routine management of VTE patients in real-world settings.

The physicians' decision about what to do after the maintenance anticoagulation period was one of the main issues addressed in the present study. Anticoagulant treatment was stopped in only one-fifth of all included patients, whereas anticoagulant therapy was extended in about half of them, and an indication for continuing treatment using various antithrombotic agents was given to the remaining patients. Though with important differences among countries, the therapeutic decisions did not seem to be predominantly influenced by the unprovoked or provoked nature of the index event, as shown by the fact that anticoagulation was extended in the same proportion of the two types of patients ( $51.7 \%$ vs. $49.3 \%$, respectively). This appears to be in contrast with what suggested by experts [2] and international guidelines [1] which have recommended at least 3 months of anticoagulation for all VTE patients and to consider extension of treatment in those with unprovoked events who have a non-high risk of bleeding. However, this result, fully consistent with what Italian vascular doctors decided in a cohort of VTE patients [12], indicates that many physicians in the everyday clinical practice of different countries prefer not to comply with a pretended obligation dictated by the classification as unprovoked/provoked event, but rather to try and assess the multifactorial individual recurrence risk. Indeed, at the multivariable analysis, the provoked/unprovoked nature of the event along with its site (PE or not), the presence of PTS signs and the presence of concomitant diseases, significantly affected the probability to continue with anticoagulation or antithrombotic treatment, rather than stopping. In contrast with international guidelines [1] and experts $[2,14]$ which indicate that male patients are at higher risk of recurrences than females and therefore that sex can be used to stratify patients for their risk and decide the extension of anticoagulation, in the present study, sex was not a factor determining the therapeutic decision, as well as age and presence of risk factors for cardiovascular diseases.

Another relevant result of this study is that many participant physicians seemed to be worried about completely stopping any treatment after the maintenance phase and limited this decision only to patients considered at low risk of recurrence, especially to those with IDDVT (31\% of them stopped any treatment). An extended anticoagulant treatment was prescribed preferably to patients estimated at very high risk of recurrence; whereas treatment with antithrombotic agents, mainly sulodexide or aspirin, was suggested to many patients, likely to maintain a kind of protection against recurrences though using drugs at lower risk of bleeding, and probably also at lower cost.

\section{Limitations}

Our study has important limitations. Patients were included from clinical centers active in countries which presented big differences, for many important aspects, differences that were impossible to adjust. Furthermore, the number of involved centers and of patients included in each country do not allow to draw general conclusions on the clinical practice adopted in each country. Finally, patient information was collected in a prospective observational registry in which all the therapeutic decisions were left to the attending physicians. For these reasons, the interpretation of our findings requires caution. We believe, however, that in the present "global" world, an effort to assess which is a prevalent approach to VTE patient management in the real-world setting of different countries is of value. It is worth promoting a comparison of everyday therapeutic procedures adopted in different countries.

In conclusion, this study provided information prospectively collected on the management of patients with recent VTE, included from clinical centers active in seven countries that are different for many important aspects. As expected, many differences in VTE patient management were found among the countries and also some similarities. DOACs were the most widely used anticoagulant drugs that most patients received for maintenance anticoagulation up to 180 days. After maintenance period, any treatment was stopped in $20 \%$ of patients, whereas anticoagulant drugs were continued in half of patients, regardless of the classification of the index event as unprovoked or provoked; antithrombotic drugs (especially sulodexide and aspirin) were prescribed to the remaining patients. 


\section{Appendix 1}

\section{List and composition of the study boards}

\section{Core team}

\begin{tabular}{|c|c|}
\hline Core Team Member & $\begin{array}{l}\text { Prof. Jiří Matuška } \\
\text { Clinical Trial Centre, Hodonin, Czechia } \\
\text { e-mail: jiri.matuska@ @matmed.cz }\end{array}$ \\
\hline Core Team Member & $\begin{array}{l}\text { Prof. German Y. Sokurenko } \\
\text { North-West Mechnikov State Medical } \\
\text { University, St. Petersburg, Russia } \\
\text { e-mail: german_sokurenko@ mail.ru }\end{array}$ \\
\hline $\begin{array}{l}\text { Core Team Member and } \\
\text { DMSB Member }\end{array}$ & $\begin{array}{l}\text { Prof. Gualtiero Palareti } \\
\text { University of Bologna (ret.), Italy } \\
\text { e-mail: gualtiero.palareti@unibo.it }\end{array}$ \\
\hline $\begin{array}{l}\text { Core Team Member and } \\
\text { DMSB Member }\end{array}$ & $\begin{array}{l}\text { Prof. Giuseppe Maria Andreozzi } \\
\text { Past Director, Angiology Unit, University } \\
\text { of Padua, Italy } \\
\text { e-mail: gm.andreozzi@gmail.com }\end{array}$ \\
\hline $\begin{array}{l}\text { Core Team Member and } \\
\text { DMSB Member }\end{array}$ & $\begin{array}{l}\text { Prof. Angelo A. Bignamini } \\
\text { University of Milan, Italy } \\
\text { e-mail: angelo@aabignamini.it }\end{array}$ \\
\hline
\end{tabular}

\section{Responsible parties}

\begin{tabular}{|c|c|c|}
\hline Promoter & $\begin{array}{l}\text { Prof. Gualtiero } \\
\text { Palareti } \\
\text { President, Fon- } \\
\text { dazione Arianna } \\
\text { Anticoagulazione }\end{array}$ & $\begin{array}{l}\text { info@ fondazionear- } \\
\text { ianna.org }\end{array}$ \\
\hline $\begin{array}{l}\text { Interna- } \\
\text { tional Study Coor- } \\
\text { dinator and }\end{array}$ & $\begin{array}{l}\text { Dr. Jiří Matuška } \\
\text { Clinical Trial Centre, } \\
\text { Hodonin, }\end{array}$ & $\begin{array}{l}\text { jiri.matuska@matmed } \\
\quad \mathrm{cz}\end{array}$ \\
\hline $\begin{array}{l}\text { National Study Coor- } \\
\text { dinator, Czechia }\end{array}$ & Czechia & \\
\hline $\begin{array}{l}\text { National Study Coor- } \\
\text { dinator, Russia }\end{array}$ & $\begin{array}{l}\text { Prof. Victor Barinov } \\
\text { Department of } \\
\text { Surgery of Central } \\
\text { State Medical } \\
\text { Academy of the } \\
\text { President Admin- } \\
\text { istration of Rus- } \\
\text { sian Federation, } \\
\text { Clinical hospital } \\
\text { N. } 1 \text { "Volynskaya", } \\
\text { Moscow, Russia }\end{array}$ & vicbarin@mail.ru \\
\hline $\begin{array}{l}\text { National Study Coor- } \\
\text { dinator, Tunisia }\end{array}$ & $\begin{array}{l}\text { Prof. Kamel } \\
\text { Bouslama } \\
\text { Faculty of Medicine } \\
\text { of Tunis, Tunisia }\end{array}$ & $\begin{array}{l}\text { kamel.bouslama387@ } \\
\text { gmail.com }\end{array}$ \\
\hline
\end{tabular}

\begin{tabular}{|c|c|c|}
\hline $\begin{array}{l}\text { National Study Coor- } \\
\text { dinator, China }\end{array}$ & $\begin{array}{l}\text { Prof. Young-Jun Li } \\
\text { Peking Union Medi- } \\
\text { cal College, Chi- } \\
\text { nese Academy of } \\
\text { Medical Sciences, } \\
\text { Beijing, China }\end{array}$ & $\begin{array}{l}\text { liyongjun4679@ } \\
\text { bjhmoh.cn }\end{array}$ \\
\hline $\begin{array}{l}\text { National Study Coor- } \\
\text { dinator, Slovakia }\end{array}$ & $\begin{array}{l}\text { Assoc. Prof. Juraj } \\
\text { Madaric } \\
\text { National Institute } \\
\text { of Cardiovascular } \\
\text { Diseases, Brati- } \\
\text { slava, Slovakia }\end{array}$ & $\begin{array}{l}\text { madaricjuraj@gmail. } \\
\text { com }\end{array}$ \\
\hline $\begin{array}{l}\text { National Study Coor- } \\
\text { dinator, Portugal }\end{array}$ & $\begin{array}{l}\text { Prof. Armando } \\
\text { Mansilha } \\
\text { University of Porto, } \\
\text { Portugal }\end{array}$ & $\begin{array}{l}\text { vascular.mansilha@ } \\
\text { gmail.com }\end{array}$ \\
\hline $\begin{array}{l}\text { National Study Coor- } \\
\text { dinator, Poland }\end{array}$ & $\begin{array}{l}\text { Prof. Tomasz } \\
\text { Urbanek } \\
\text { Medical University } \\
\text { of Silesia, Kato- } \\
\text { wice, Poland }\end{array}$ & $\begin{array}{l}\text { urbanek.tom@interia. } \\
\text { pl }\end{array}$ \\
\hline Study Statistician & $\begin{array}{l}\text { Prof. Angelo A. } \\
\text { Bignamini } \\
\text { Dept. of Pharmaceu- } \\
\text { tical Sciences } \\
\text { University of Milan } \\
\text { (Italy) }\end{array}$ & $\begin{array}{l}\text { angelo@aabignamini. } \\
\text { it }\end{array}$ \\
\hline Study Monitor & $\begin{array}{l}\text { Dr. Michela Cini } \\
\text { Arianna Anticoag- } \\
\text { ulazione Founda- } \\
\text { tion } \\
\text { Bologna, Italy }\end{array}$ & $\begin{array}{l}\text { m.cini@fondazionear- } \\
\text { ianna.org }\end{array}$ \\
\hline Database Manager & $\begin{array}{l}\text { Dr. Ilaria Caldirola } \\
\text { OFFICINEBIT.CH } \\
\text { sagl } \\
\text { Chiasso, Switzerland }\end{array}$ & ilaria@officinebit.ch \\
\hline
\end{tabular}

CRO used in the countries:

- Medart, Warsaw, Poland

- Datamedica, Amadora, Portugal

- Value Outcomes s.r.o. Praha, Czechia

- Poseidon CRO, Ariana, Tunisia

- JD Software, Bratislava, Slovakia

No professional CROs were necessary in China and Russia, where the local Principal Investigators were able to reach the study authorization from the referent health regulatory authorities.

Supplementary Information The online version contains supplementary material available at https://doi.org/10.1007/s11739-021-02765-1.

Acknowledgements Alfasigma (Bologna, Italy) supported the study by offering an unrestricted grant to the "Arianna Anticoagulazione" Foundation, specifically dedicated to the realization of this study. China: Jian-long Liu, Beijing Jishuitan Hospital, Beijing; Fu-xian Zhang, Beijing Shijitan Hospital CMU, Beijing; Tao Yang, Shanxi Dayi Hospital, Taiyuan; Wei Ye, Peking Union Medical College Hosp., Beijing; 
Qi Wang, Tongji Hospital, Huazhong University of Science \& Technology, Wuhan; Xiangchen Dai, Tianjin Medical University General Hospital, Tianjin; Zhen Li, The First Affiliated Hospital of Zhengzhou University, Zhengzhou; Jian Zhang, The First Hospital of China Medical University, Shenyang; Yong-jun Li, Beijing Hospital of the Ministry of Health, Beijing; Jin-song Wang, The FirstAffiliated Hospital, Sun Yet-sen University, Guangzhou; Ju He, Tianjin First Center Hospital, Tianjin; Yi-qing Li, Union Hospital, Huazhong University of Science \& Technology, Wuhan; Xiao-qiang Li, Nanjing Drump Tower Hospital, Nanjing; Zhong Chen, Beijing Anzhen Hospital, Capital Medical University, Beijing; Ai-min Qian, No.2 Hospital Affiliated to Suzhou University, Suzhou. Czechia: Monika Vogelová, Poliklinika Modřany, Praha; Stanislava Králová, Angios s.r.o., Prostějov; Jana Hirmerová, FN Plzeň, Plzeň; Jiří Matuška, Clinical Trial Center Hodonín, Hodonín; Stanislav Śárník, Angiologie Brno, Brno. Poland: Marcin Gabriel, Gab-med., Poznań; Wojciech Sydor, 1. SCM-Specjalistyczne Centrum Medyczne Chirurgii Małoinwazyjnej, Kraków; Filip Szymański, Premium Medical, Wielgoś \& Partners sp. z o.o, Warszawa; Tomasz Urbanek, Gabinet Lekarski, lekarz medycyny Tomasz Urbanek, Katowice; Zbigniew Krasiński, Indywidualna Specjalistyczna Praktyka Lekarska Medicus et Media, Poznań; Adam Zieliński, Centrum Medyczne doktorA, Warszawa; Anna Sojda-Szarnecka, Prywatny Gabinet Specjalistyczny Anna Szarnecka-Sojda, Kielce; Tomasz Pelak, Indywidualna Praktyka Lekarska lek.med. Tomasz Pelak, Lubin; Wojciech Skibiński, Klnika Chirurgii Naczyniowej FLEBO, Sanok; Włodzimierz Hendiger, Centrum Medyczne Hendimed, Łódź; Tomasz AleksiejewKleszczyński, Centrum Medyczne Chirurgia Naczyń, Kraków; Tomasz Grzela, Klinika Flebologii Sp. z o.o., Warszawa; Andrzej Szuba, Indywidualna Specjalistyczna Praktyka Lekarska Andrzej Szuba, Wrocław; Tomasz Zubilewicz, Prywatna Specjalistyczna Praktyka Lekarska prof. Tomasz Zubilewicz, Lublin; Eugeniusz Majewski, Indywidulana Specjalistyczna Praktyka Lekarska-Gabinet Lekarski Choroby Tętnic i Żył, Katowice; Jerzy Głowiński, Indywidualna Specjalistyczna Praktyka Lekarska Jerzy Głowiński, Białystok; Michał Molski, Szpital Eskulap-Centrum Leczenia Chorób Serca i Naczyń, Bydgoszcz; Krzysztof J Filipiak, Boston Clinic Sp.z o.o, Warszawa; Marcin Kucharzewski, Marcin Kucharzewski Indywidulana Praktyka Lekarska, Katowice. Portugal: Rita Augusto, Centro Hospitalar de Vila Nova de Gaia / Espinho, Vila Nova de Gaia; João Vaconcelos, Centro Hospitalar do Tâmega e Sousa, Penafiel; Isabel Cássio, Hospital do Divino Espírito Santo, Ponta Delgada; Ana Garcia, Centro Hospitalar Lisboa Central-Hospital de Santa Marta, Lisboa; António Simões, Hospital de São Teotónio, Viseu. Russia: Yuriy Chervyakov, Medical Center Diagnostics and Prevention Plus, Yaroslavl; Larisa Lyudkova, Regional Budget Health care Institution Krasnoyarsk Interdistrict hospital №5, Krasnoyarsk; Victor Barinov, Clinical Hospital No. 1 of the Presidential Administration of the Russian Federation, Moscow; Ilya Schastlivtsev, Clinical Hospital No. 1 of the Presidential Administration of the Russian Federation, Moscow; Oleg Guzhkov, State Hospital №9, Yaroslavl; Sergey Katorkin, FSBEE HE «Samara State Medical University», Samara; Tigran Lazaryan, Municipal clinic №134 (subsidiary 1), Moscow; Igor Prostov, Clinic of Rostov State Medical university, Rostov; Oleg Skorobogatov, Sanitary part 8 of the federal medicobiological agency of Russia, Serpukhov; Elena Burleva, Municipal hospital №40, Ekaterinburg; Anton Scarubsky, Krasnoyarsk Interdistrict Diagnostic Center, Krasnoyarsk; Alexey Petrikov, Altai State Medical University City hospital №5, Barnaul; Georgy Smirnov, State budget Healthcare Institution of Yaroslavl Region "Clinical hospital \#10", Yaroslavl; Alexey Fokin, Regional clinical hospital №3, Chelyabinsk; Igor Sonkin, Road Clinical hospital, S-Petersburg; Sergey Bushnin, Doctor Vein, Khabarovsk; Elena Murzina, Medical Hospital Neftyanik, Tyumen; Vladimir Zelinsky, EMC (United Medical Systems), S-Petersburg; Alexandr Bogdan, PhleboArt Clinic, Krasnodar; Roman Bredikhin, Interregional Clinical and Diagnostic Center, Kazan; Ovsep Mandzhikian, Municipal hospital named after Eramishancev, Moscow; Anton Isaev, Garant clinic, Moscow. Slovakia: Martina Padúchová,
MEDENA s.r.o, Trnava; Andrej Džupina, ALIAN, sro, Bardejov; Viera Štvrtinová, University Hospital, 1st Dep. of internal medicine, Comenius University, Bratislava; Melinda Malá, M.M.-Angio s.r.o., Dunajská Streda; Juraj Mad’arič, The National Institute of Cardiovascular Diseases, Bratislava; Lubomíra Javorčíková, LION-MED s.r.o., Bratislava; Dasa Kmecová, ANGIOCARE, s.r.o., Košice. Tunisia: Meya Abdelkefi, Regional Hospital of Ben Arous, Ben Arous; Kamel Bouslama, Mongi Slim hospital, La Marsa; Raja Elamri, Hospital Mohamed Taher Mamouri, Nabeul; Fatma Boussema, Habib Thameur Hospital, Tunis; Chedia Kechrid, Sahloul Hospital, Sousse

\section{Compliance with ethical standards}

Conflict of interest Gualtiero Palareti has received consulting fees from Alfasigma. Angelo Bignamini has received consulting fees from Bayer Healthcare and Alfasigma. German Sokurenko has received lectures fees from Alfasigma, Bayer Healthcare, Pfizer. Tomasz Urbanek has received consulting and lectures fees from Alfasigma. The other authors declare no conflict of interest.

Human and animal rights statement The study protocol was approved by the local ethics committees and was conducted in accordance with the Declaration of Helsinki.

Informed consent Written informed consent was collected according to local practice.

Open Access This article is licensed under a Creative Commons Attribution 4.0 International License, which permits use, sharing, adaptation, distribution and reproduction in any medium or format, as long as you give appropriate credit to the original author(s) and the source, provide a link to the Creative Commons licence, and indicate if changes were made. The images or other third party material in this article are included in the article's Creative Commons licence, unless indicated otherwise in a credit line to the material. If material is not included in the article's Creative Commons licence and your intended use is not permitted by statutory regulation or exceeds the permitted use, you will need to obtain permission directly from the copyright holder. To view a copy of this licence, visit http://creativecommons.org/licenses/by/4.0/.

\section{References}

1. Kearon C, Akl EA, Ornelas J, Blaivas A, Jimenez D, Bounameaux H, Huisman M, King CS, Morris TA, Sood N, Stevens SM, Vintch JR, Wells P, Woller SC, Moores L (2016) Antithrombotic therapy for VTE disease: CHEST guideline and expert panel report. Chest 149:315-352

2. Kearon C, Kahn SR (2020) Long-term treatment of venous thromboembolism. Blood 135:317-325

3. Schulman S, Kearon C, Kakkar AK, Mismetti P, Schellong S, Eriksson H, Baanstra D, Schnee J, Goldhaber SZ (2009) Dabigatran versus warfarin in the treatment of acute venous thromboembolism. N Engl J Med 361:2342-2352

4. Bauersachs R, Berkowitz SD, Brenner B, Buller HR, Decousus $\mathrm{H}$, Gallus AS, Lensing AW, Misselwitz F, Prins MH, Raskob GE, Segers A, Verhamme P, Wells P, Agnelli G, Bounameaux H, Cohen A, Davidson BL, Piovella F, Schellong S (2010) Oral rivaroxaban for symptomatic venous thromboembolism. N Engl J Med 363:2499-2510

5. Buller HR, Prins MH, Lensin AW, Decousus H, Jacobson BF, Minar E, Chlumsky J, Verhamme P, Wells P, Agnelli G, Cohen A, Berkowitz SD, Bounameaux H, Davidson BL, Misselwitz F, 
Gallus AS, Raskob GE, Schellong S, Segers A (2012) Oral rivaroxaban for the treatment of symptomatic pulmonary embolism. N Engl J Med 366:1287-1297

6. Agnelli G, Buller HR, Cohen A, Curto M, Gallus AS, Johnson M, Masiukiewicz U, Pak R, Thompson J, Raskob GE, Weitz JI (2013) Oral apixaban for the treatment of acute venous thromboembolism. N Engl J Med 369:799-808

7. Agnelli G, Buller HR, Cohen A, Curto M, Gallus AS, Johnson M, Porcari A, Raskob GE, Weitz JI (2013) Apixaban for extended treatment of venous thromboembolism. N Engl J Med 368:699-708

8. Buller HR, Decousus H, Grosso MA, Mercuri M, Middeldorp S, Prins MH, Raskob GE, Schellong SM, Schwocho L, Segers A, Shi M, Verhamme P, Wells P (2013) Edoxaban versus warfarin for the treatment of symptomatic venous thromboembolism. N Engl J Med 369:1406-1415

9. Weitz JI, Lensing AWA, Prins MH, Bauersachs R, Beyer-Westendorf J, Bounameaux H, Brighton TA, Cohen AT, Davidson BL, Decousus H, Freitas MCS, Holberg G, Kakkar AK, Haskell L, van Bellen B, Pap AF, Berkowitz SD, Verhamme P, Wells PS, Prandoni P (2017) Rivaroxaban or aspirin for extended treatment of venous thromboembolism. N Engl J Med 376:1211-1222

10. von Elm E, Altman DG, Egger M, Pocock SJ, Gotzsche PC, Vandenbroucke JP, Initiative S (2007) The strengthening the reporting of observational studies in epidemiology (STROBE) statement: guidelines for reporting observational studies. Ann Intern Med 147:573-577
11. Palareti G, Antonucci E, Legnani C, Mastroiacovo D, Poli D, Prandoni P, Tosetto A, Pengo V, Testa S, Ageno W, Investigators SR (2020) Bleeding and thrombotic complications during treatment with direct oral anticoagulants or vitamin $\mathrm{K}$ antagonists in venous thromboembolic patients included in the prospective, observational START2-register. BMJ Open 10:e040449

12. Antonucci E, Migliaccio L, Abbattista M, Caronna A, De Marchi S, Di Giorgio A, Di Giulio R, Lerede T, Garzia MG, Martinelli I, Mastroiacovo D, Marzolo M, Montevecchi E, Pastori D, Pignatelli P, Poli D, Ria L, Santoliquido A, Testa S, Palareti G, Investigators SPV (2020) Treatment decision-making of secondary prevention after venous thromboembolism: data from the reallife START2-POST-VTE register. Clin Appl Thromb Hemost 26:1076029620945792

13. Tagalakis V, Patenaude V, Kahn SR, Suissa S (2014) Treatment patterns of venous thromboembolism in a real-world population: the Q-VTE study cohort. Thromb Res 134:795-802

14. Rodger MA, Le Gal G (2018) Who should get long-term anticoagulant therapy for venous thromboembolism and with what? Blood Adv 2:3081-3087

Publisher's Note Springer Nature remains neutral with regard to jurisdictional claims in published maps and institutional affiliations. 